\title{
Reliability Analysis of High Rockfill Dam Stability
}

\author{
Ping Yi, Jun Liu, and Chunlei Xu \\ School of Civil Engineering, Dalian University of Technology, Dalian 116024, China \\ Correspondence should be addressed to Ping Yi; yiping@dlut.edu.cn
}

Received 11 September 2014; Accepted 17 April 2015

Academic Editor: Rafael J. Villanueva

Copyright (C) 2015 Ping Yi et al. This is an open access article distributed under the Creative Commons Attribution License, which permits unrestricted use, distribution, and reproduction in any medium, provided the original work is properly cited.

\begin{abstract}
A program 3DSTAB combining slope stability analysis and reliability analysis is developed and validated. In this program, the limit equilibrium method is utilized to calculate safety factors of critical slip surfaces. The first-order reliability method is used to compute reliability indexes corresponding to critical probabilistic surfaces. When derivatives of the performance function are calculated by finite difference method, the previous iteration's critical slip surface is saved and used. This sequential approximation strategy notably improves efficiency. Using this program, the stability reliability analyses of concrete faced rockfill dams and earth core rockfill dams with different heights and different slope ratios are performed. The results show that both safety factors and reliability indexes decrease as the dam's slope increases at a constant height and as the dam's height increases at a constant slope. They decrease dramatically as the dam height increases from $100 \mathrm{~m}$ to $200 \mathrm{~m}$ while they decrease slowly once the dam height exceeds $250 \mathrm{~m}$, which deserves attention. Additionally, both safety factors and reliability indexes of the upstream slope of earth core rockfill dams are higher than that of the downstream slope. Thus, the downstream slope stability is the key failure mode for earth core rockfill dams.
\end{abstract}

\section{Introduction}

Rockfill dams are commonly used geotechnical infrastructures for water management. One of the critical aspects of rockfill dam design is stability analysis, that is, the computation of safety factors (Chen and Morgenstern 1983 [1]; Janbu 1973 [2]). A deterministic approach is traditionally utilized for this analysis. However, as natural materials, rockfill and earth core exhibit large uncertainties in their shear strength parameters, dry bulk density, and other pertinent properties, which cannot be handled in the traditional deterministic methods. Therefore, the application of probabilistic reliability concepts to the stability analysis of dams has drawn increasing attention over the past two decades (Wolff 1996 [3]; Bureau 2003 [4]; Yanmaz and Beser 2005 [5]). Duncan (2000) [6] pointed out that the reliability analysis offers a useful supplement to conventional stability analyses, because the resultant reliability index contains more information than the deterministic safety factor.

The limit equilibrium method (LEM) and the strength reduction method (SRM) on the basis of the finite element method (FEM) or finite difference method (FDM) are currently popular methods among engineers for slope stability analysis (Hassan and Wolff 1999 [7]; Griffiths and Fenton 2004 [8]). Whether LEM or SRM is used, the stability analysis of rockfill dams is a time-consuming process and the calculated safety factor is an implicit function of basic variables, such as materials' shear strength parameters and dry bulk density. Then in the reliability analysis, the performance function is implicit and many iterations of calculating the safety factor have to be performed to obtain the reliability index. Therefore, despite its potential value, reliability theory has not been widely adopted in geotechnical engineering because of huge computational cost.

The response surface method (RSM) has been developed to deal with implicit performance functions and $\mathrm{Xu}$ and Low (2006) [9] utilized RSM combined with FEM to calculate the reliability index of slopes. However, the surrogate performance function from the RSM may cause a deviation from the exact model (Luo et al. 2012 [10]). When no such surrogate performance function is used, most previous reports have utilized the mean value first-order second-moment (FOSM, Hassan and Wolff 1999 [7]) method or its extension, the point-estimate method (Rosenblueth 1975 [11]), to calculate the approximate reliability index of slope stability. In some papers, the distributions of the random variables are not 
mentioned at all, and the reliability index is calculated by the performance function's mean value divided by its standard deviation (Duncan 2000 [6]). In others, two expressions are given based on the normal distribution and the lognormal distribution (Liang et al. 1999 [12]). However, it is well known in reliability analysis that different values of the reliability index might be obtained for different mathematical forms of the same limit state function when FOSM is used (Hasofer and Lind 1974 [13]). Baecher and Christian (2003) [14] have studied such problem in geotechnical engineering. Accordingly, the first-order reliability method (FORM) is recommended and has gradually been accepted by researchers despite its complexity (Babu and Srivastava 2010 [15]). In this paper, FORM is utilized.

Although there are some commercial software programs, for example, PLAXIS (FEM) and FLAC (FDM), for the slope stability analysis, software package combining the slope stability and reliability analysis is rare (Cho 2009 [16]). In this paper, a self-developed program 3DSTAB, which integrates slope stability analysis and reliability analysis, is introduced. LEM is employed in this program to calculate safety factors and FORM, more precisely, the HL-RF iterative algorithm, is utilized to compute reliability indices. Three examples reported in recent literature are studied and the comparisons prove the validity and accuracy of 3DSTAB. Then two typical kinds of rockfill dams, that is, concrete faced rockfill dams and earth core rockfill dams, are considered. Rockfill dams with different heights over $100 \mathrm{~m}$ and different slope ratios are analyzed to study the relationships of the safety factors and reliability indices to the dam height and dam slope ratio parameter.

\section{Reliability Analysis}

To perform the reliability analysis of the slope stability of dams, a performance function or limit state function, $g(\mathbf{x})$, should be defined to identify the failure state $(g(\mathbf{x})<0)$ and safety state $(g(\mathbf{x})>0)$, where $\mathbf{x}=\left(x_{1}, x_{2}, \ldots, x_{n}\right)$ is a random variable vector. The following formulation of the performance function (Phoon 2008 [17]) is widely utilized and adopted in this paper:

$$
g(\mathbf{x})=g\left(x_{1}, x_{2}, \ldots, x_{n}\right)=F_{s}\left(x_{1}, x_{2}, \ldots, x_{n}\right)-1.0,
$$

where $F_{s}$ is the safety factor and the prescribed acceptable safety factor is 1.0 (Liang et al. 1999 [12]). The probability of failure can be defined as

$$
P_{f}=P(g(\mathbf{x})<0)=\int_{g(\mathbf{x}) \leq 0} f(\mathbf{x}) \mathrm{d} \mathbf{x}
$$

in which $f(\mathbf{x})$ is the joint probability density function of $\mathbf{x}$. Because the multidimensional integral in (2) can be very difficult and nearly impossible, the reliability index $\beta$ is generally calculated in engineering, and the failure probability is estimated by

$$
P_{f} \approx \Phi(-\beta)
$$

$\Phi(\cdot)$ is the standard normal cumulate distribution function.
In slope stability reliability analysis, most previous reports have utilized FOSM (Hassan and Wolff 1999 [7]) method or its extension, the point-estimate method (Rosenblueth 1975 [11]), to calculate the reliability index to avoid heavy computational burden. However when FOSM is used, different values of the reliability index might be obtained for different mathematical forms of the same limit state function (Hasofer and Lind 1974 [13]) and Baecher and Christian (2003) [14] have studied such problem in geotechnical engineering. Accordingly, FORM has gradually been accepted by researchers despite its complexity (Babu and Srivastava 2010 [15]).

In FORM, the original random vector $\mathbf{x}$ is transformed to a standard Gaussian vector $\mathbf{u}$ firstly, expressed as $\mathbf{x}=\mathbf{T}(\mathbf{u})$ (Hohenbichler and Rackwitz 1981 [18]) and the performance function $g(\mathbf{x})=g(\mathbf{T}(\mathbf{u}))=G(\mathbf{u})$. Then the reliability index $\beta$ is the minimum distance from the coordinate origin to the limit state surface in $\mathbf{u}$-space, and its computation is formulated as the following optimization problem:

$$
\begin{aligned}
\min & \|\mathbf{u}\| \\
\text { s.t. } & G(\mathbf{u})=0 \\
\text { so that } & \beta=\left\|\mathbf{u}^{*}\right\|,
\end{aligned}
$$

where $\mathbf{u}^{*}$ is the design point on the limit state surface in $\mathbf{u}$-space. The design point can be located by various optimization algorithms, such as the gradient projection (GP) method, the augmented Lagrangian (AL) method, and the sequential quadratic programming (SQP) method (Val et al. 1996 [19]). Among various methods that have been evaluated for application on structural reliability, an iterative algorithm, the HL-RF algorithm (Hasofer and Lind 1974 [13], Rackwitz and Flessler 1978 [20]), is found to be very efficient as it requires the least amount of storage and computation in each step in comparison with other methods (Liu and der Kiureghian 1991 [21]). The HL-RF algorithm computes the reliability index by the following iterative formulas:

$$
\begin{aligned}
\beta^{k} & =\frac{G\left(\mathbf{u}^{k}\right)-\left(\nabla_{\mathbf{u}} G\left(\mathbf{u}^{k}\right)\right)^{T} \mathbf{u}^{k}}{\left\|\nabla_{\mathbf{u}} G\left(\mathbf{u}^{k}\right)\right\|}, \\
\mathbf{u}^{k+1} & =-\beta^{k} \frac{\nabla_{\mathbf{u}} G\left(\mathbf{u}^{k}\right)}{\left\|\nabla_{\mathbf{u}} G\left(\mathbf{u}^{k}\right)\right\|} .
\end{aligned}
$$

The iteration is completed when the absolute change of the design points between two subsequent iterations is smaller than a prescribed small quantity, for example, 0.001. The HL$\mathrm{RF}$ algorithm can generally obtain the results with enough accuracy after some iterations and is utilized in this paper.

\section{3DSTAB Program}

The slope stability analysis and reliability analysis are combined in the self-developed program 3DSTAB. LEM, which has received wide acceptance because of its simplicity, is utilized to calculate the slope stability safety factor. FORM, more precisely, the HL-RF iterative algorithm, is utilized to compute the reliability index. 


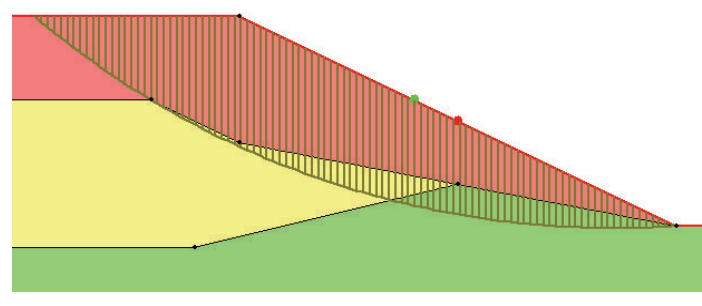

(a) Result computed by $3 \mathrm{DSTAB}$

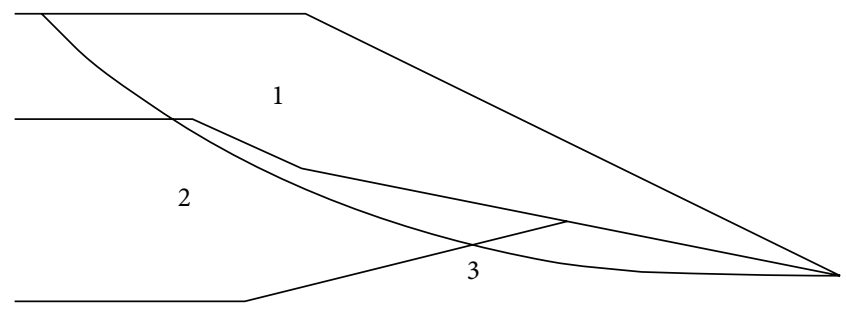

(b) Result in [31] (Chen, 2003)

FIGURE 1: Comparison of the critical slip circles in the example of a multilayered soil slope.

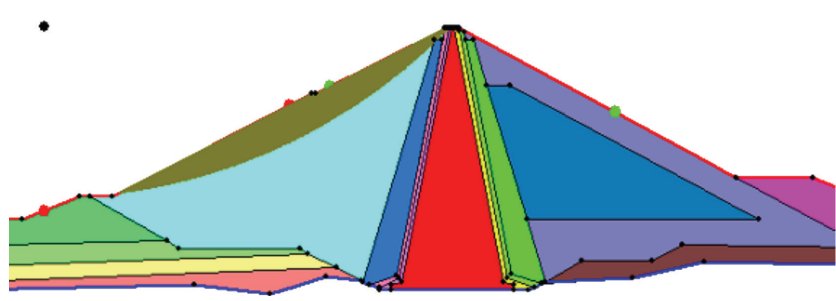

(a) Result computed by 3DSTAB

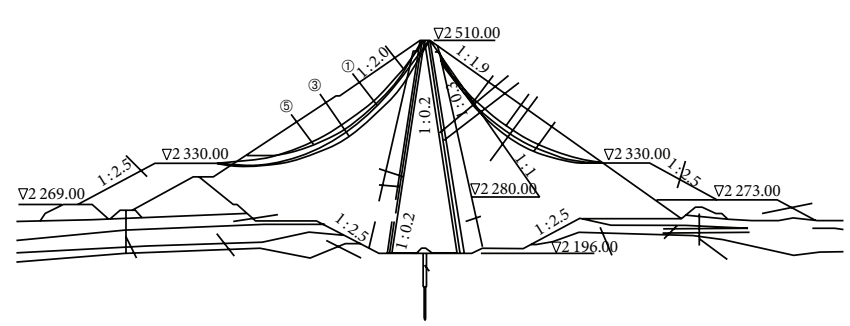

(b) Result in [32] (Wu et al. 2009)

FIGURE 2: Comparison of the critical slip circles of the Shuangjiangkou core-wall rockfill dam.

The Bishop method (Bishop 1955 [22]), simple Janbu method (Janbu 1968 [23]), or the global analysis method (Zheng 2009 [24], Zheng 2012 [25]) can be chosen under static conditions. Although the program can perform $2 \mathrm{D}$ and 3D slope stability analyses, just 2D analysis is performed in this paper because Duncan (1996) [26] pointed out that the safety factors resulting from $3 \mathrm{D}$ analyses are normally greater than those from $2 \mathrm{D}$ analyses. To calculate the safety factor of the slope stability, mean values are assigned to the variables and the particle swarm optimization (PSO) method is applied to search the critical slip surface, which is referred to as the critical deterministic surface (Li et al. 2007 [27]). In reliability analysis, the critical slip surface is searched, and the corresponding safety factor is determined for every realization of the random variables in every iteration. Several iterations are needed to calculate the reliability index through the HL-RF algorithm. The critical slip surface for the final realization, $\mathbf{u}^{*}$, is referred to as the critical probabilistic slip surface. Some previous papers only calculated the reliability index $\beta$ corresponding to the critical deterministic surface (Calle 1985 [28]; Honjo and Kuroda 1991 [29]). However, some researchers have shown that these two kinds of slip surfaces do not generally coincide (Liang et al. 1999 [12]; Hassan and Wolff 1999 [7]). Here, we calculate $\beta$ corresponding to the critical probabilistic surface. However, when the derivative $\nabla_{\mathbf{u}} G\left(\mathbf{u}^{k}\right)$ is computed by the finite difference method in every iteration, we do not search the critical slip surface anymore, and the previous critical slip surface is saved and utilized. This kind of sequential approximation strategy is widely utilized in structural optimization and reliability-based optimization (Yi et al. 2008 [30]).
To prove the accuracy and validity of 3DSTAB, three examples that have recently appeared in literature are restudied and compared. The examples include an example of multilayered soil (Chen 2003 [31]), the Shuangjiangkou core-wall rockfill dam with a height of $314 \mathrm{~m}$ (Wu et al. 2009 [32]) and the Nuozhadu core-wall rockfill dam with a height of $261.5 \mathrm{~m}$ (L.-H. Chen and Z.-Y. Chen 2007 [33]). The computational models and the statistical information of the random parameters are the same as those in the corresponding literature. The comparisons of the critical slip circles are shown in Figures 1-3. The safety factors and the reliability indices are listed in Table 1 . The figures and the table show that the results computed by 3DSTAB program are similar to the results reported in other publications and are accurate and reliable.

\section{Stability Reliability Analysis of High Rockfill Dams}

As natural materials, rockfill and earth core exhibit large uncertainties. In this paper, the dry bulk densities and shear strength parameters, including the linear strength parameters of earth core material and the nonlinear strength parameters of rockfill material, are taken as random variables. Based on the statistical properties of the random variables reported in literature, stability reliability analyses of two typical kinds of rockfill dams with different heights over $100 \mathrm{~m}$ and different slope ratios are performed using the self-developed program 3DSTAB. The effects of dam height and slope ratio on 


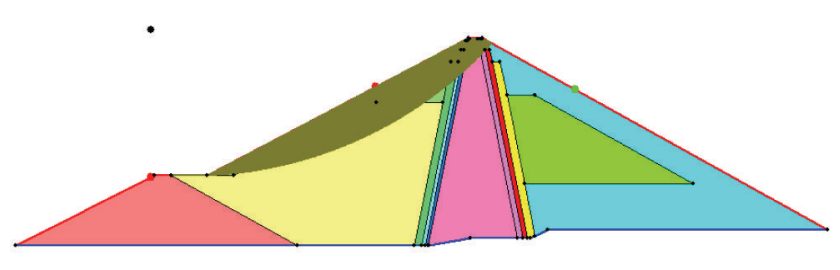

(a) Result computed by 3DSTAB

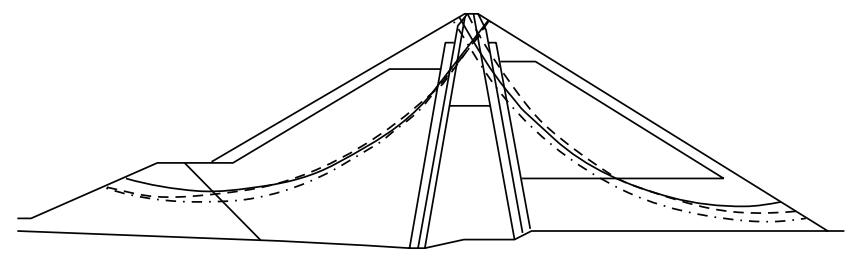

(b) Result in [33] (L.-H. Chen and Z.-Y. Chen 2007)

FIGURE 3: Comparison of the critical slip circles of the Nuozhadu core-wall rockfill dam.

TABLE 1: Comparison of stability analyses of the three examples.

\begin{tabular}{|c|c|c|c|c|}
\hline & \multicolumn{2}{|c|}{ Results computed by 3DSTAB } & \multicolumn{2}{|c|}{ Results in the literature } \\
\hline & $F_{s}$ & $\beta$ & $F_{s}$ & $\beta$ \\
\hline Multilayered soil slope & 1.525 & 5.121 & 1.500 & 4.963 \\
\hline Shuangjiangkou core-wall rockfill dam & 1.813 & 5.353 & - & 5.573 \\
\hline Nuozhadu core-wall rockfill dam & 1.949 & 4.185 & 1.888 & - \\
\hline
\end{tabular}

the safety factor and the reliability index of concrete faced rockfill dams and earth core rockfill dams are discussed.

4.1. Statistical Properties of Random Variables. The linear Mohr-Coulomb failure criterion is conventionally utilized to perform dam stability analyses as follows:

$$
\tau_{f}=c+\sigma_{n} \tan \Phi
$$

in which $\tau_{f}$ is the peak shear strength, $\sigma_{n}$ is the effective normal stress, $c$ is the cohesion or snap-in force, and $\Phi$ is the internal frictional angle. However, the results of many large-scale triaxial tests indicate that Mohr failure envelopes for rockfill exhibit significant nonlinearity, particularly under low and medium normal stresses. And the slope failure of a rockfill dam is just generally associated with relatively low normal stresses (Indraratna et al. 1993 [34]). Thus, the nonlinearity of the Mohr-Coulomb failure criterion cannot be neglected. Duncan (1980) [35] proposed that the drained friction angle $\Phi$ of rockfill can be evaluated from the following logarithmic expression:

$$
\Phi=\Phi_{0}-\Delta \Phi \log \left(\frac{\sigma_{3}}{P_{a}}\right)
$$

in which $\sigma_{3}$ is the smallest principal stress, $P_{a}$ is the atmospheric pressure, $\Phi_{0}$ is the value of $\Phi$ when $\sigma_{3}$ is equal to $P_{a}$, and $\Delta \Phi$ is the reduction of $\Phi$ corresponding to a $10-$ fold increase in $\sigma_{3}$. This logarithmic nonlinear shear strength criterion is widely utilized in China (Bai and Cui 1994 [36]; Lu and Yin 2004 [37]), and the Chinese "Design Code for Rolled Earth-rock Fill Dams” (SL274-2001) [38] recommends that the logarithmic expression (7) should be utilized to describe the nonlinear shear strength of rough grain materials, such as rockfill.

In this paper, we consider earth core material to have linear shear strength expressed in (6) and the main and
TABLE 2: Statistical information of earth core.

\begin{tabular}{lccc}
\hline & $\gamma\left(\mathrm{kN} / \mathrm{m}^{3}\right)$ & $c\left(\mathrm{kN} / \mathrm{m}^{3}\right)$ & $\Phi\left(^{\circ}\right)$ \\
\hline Mean value $\mu$ & 20.7 & 23.0 & 30.3 \\
Standard deviation $\sigma$ & 1.3 & 2.8 & 1.3 \\
Variation coefficient $\delta(\%)$ & 6.3 & 12.2 & 4.3 \\
Distribution type & Normal & Lognormal & Lognormal \\
\hline
\end{tabular}

subrockfill material to have the logarithmic nonlinear shear strength expressed in (7). The shear strength parameters in these expressions and the dry bulk density, $\gamma$, are taken as random parameters and their statistical information, which is reported by Xu (2010) [39], is listed in Tables 2 and 3. Because considering correlations between the parameters would only marginally increase the slope stability and its reliability (Babu and Srivastava 2010 [15]; Wu et al. 2009 [32]), the correlations are not considered here, and the obtained results are thus relatively conservative.

From Tables 2 and 3, we can see that most of the stochastic variables obey normal distribution. It has been pointed out that a normally distributed variable is defined on the real number space $\mathbf{R}$, and negative values may be given to a parameter that is positive in nature, such as $\Phi_{0}$. This would give an unreasonable lower value to the reliability index (Liang et al. 1999 [12]). The situation will be worse when the variation coefficient of the parameter is not small. So a truncated normal distribution is adopted in this study for all normally distributed parameters to avoid sampling negative values (Most and Knabe 2010 [40]). The upper limit is $\mu+3 \sigma$, and the lower limit is the larger one of $\mu-3 \sigma$ and zero, in which $\mu$ is the mean value and $\sigma$ is the standard deviation.

4.2. Stability Reliability Analysis. Two kinds of rockfill dams, that is, concrete faced rockfill dams and earth core rockfill 
TABLE 3: Statistical information of rockfill.

\begin{tabular}{|c|c|c|c|c|c|c|}
\hline & \multicolumn{3}{|c|}{ Main rockfill } & \multicolumn{3}{|c|}{ Subrockfill } \\
\hline & $\gamma\left(\mathrm{kN} / \mathrm{m}^{3}\right)$ & $\Phi_{0}\left(^{\circ}\right)$ & $\Delta \Phi\left(^{\circ}\right)$ & $\gamma\left(\mathrm{kN} / \mathrm{m}^{3}\right)$ & $\Phi_{0}\left(^{\circ}\right)$ & $\Delta \Phi\left(^{\circ}\right)$ \\
\hline Mean value $\mu$ & 21.0 & 51.2 & 8.2 & 20.8 & 48.8 & 9.4 \\
\hline Standard deviation $\sigma$ & 0.8 & 4.3 & 3.2 & 0.7 & 4.6 & 2.3 \\
\hline Variation coefficient $\delta(\%)$ & 3.8 & 8.4 & 39.0 & 3.3 & 9.4 & 24.5 \\
\hline Distribution type & Normal & Normal & Normal & Normal & Normal & Normal \\
\hline
\end{tabular}

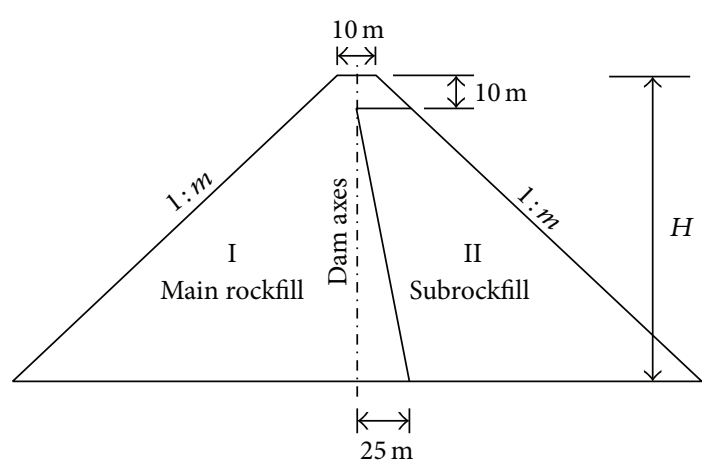

FIGURE 4: Cross section of a concrete faced rockfill dam.

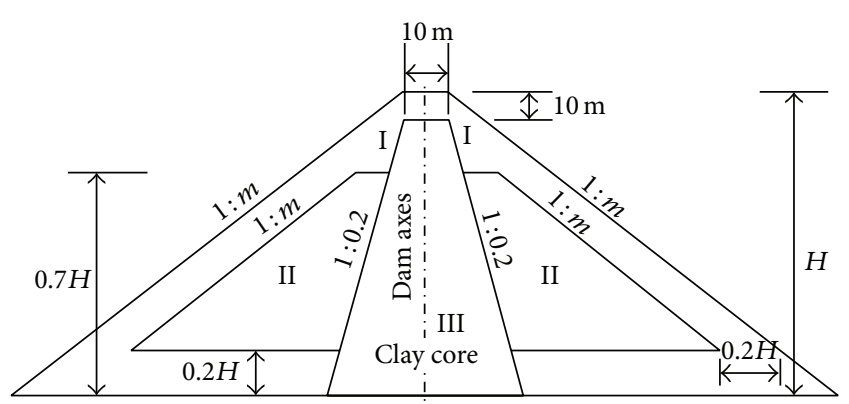

Note: the width of the clay core wall is $6 \mathrm{~m}$ when the dam height is $100 \mathrm{~m}$ or $150 \mathrm{~m}$

FIGURE 5: Cross section of an earth core rockfill dam.

dams, are analyzed and their typical cross-sectional shapes are shown in Figures 4 and 5. The dam height $H$ varies from $100 \mathrm{~m}$ to $350 \mathrm{~m}$ in intervals of $50 \mathrm{~m}$. The slope ratio is expressed as $1: m$, where $m$ can be $1.3,1.4,1.5$, or 1.6 for concrete faced rockfill dams and 1.8, 1.9, or 2.0 for earth core rockfill dams, respectively. Cushion zone and transition zone are ignored due to little effect on slope stability. The Bishop method is utilized to calculate safety factors under static conditions. The number of soil strips is $(m * H+20)$, and the soil strip width is less than $1.0 \mathrm{~m}$. The reliability index is computed through the HL-RF iterative algorithm with a maximum of 20 iterations.

The water level is set to the maximum pool level. The stability of the downstream slope is considered for concrete faced rockfill dams. The safety factors and reliability indices at different heights $(H)$ and slope ratio parameters $(m)$ are shown in Figure 6. For earth core rockfill dams, the stabilities of both the upstream and downstream slopes under steadystate seepage conditions are calculated. The results are shown in Figures 7 and 8.

Figure 6 shows that the safety factors of the downstream slopes of concrete faced rockfill dams range from 1.34 to 1.85 and the reliability indices range from 1.60 to 5.67 . Both quantities decrease as the dam height $(H)$ increases, as mentioned by Cao and Chen (1991) [41]. At the same time, both quantities decrease as the slope ratio parameter $(m)$ decreases; that is, the safety factors and the reliability indices decrease as the dam slope becomes steeper. This corresponds with the fact that the higher and the steeper dams are, the more dangerous they become. It should be noted in Figure 6 that when the dam height is relatively low (i.e., from $100 \mathrm{~m}$ to $200 \mathrm{~m}$ ), the safety factors and the reliability indices decrease dramatically as the dam height increases. Strangely, when the dam height $(H)$ exceeds $250 \mathrm{~m}$, the safety factors and the reliability indices decrease very slowly with further increases of the dam height. The stability reliability analyses of both the upstream and downstream slopes of earth core rockfill dams present the same behavior, and this deserves extra attention.

Figures 7 and 8 show the safety factors and reliability indices of the upstream and downstream slopes of earth core rockfill dams, respectively. These quantities also decrease as the dam height $(H)$ increases and the slope factor $(m)$ decreases. The safety factors of the upstream slopes of earth core rockfill dams range from 1.80 to 2.35 , and the reliability indices range from 4.03 to 11.52 . The ranges are from 1.70 to 2.23 for $F_{s}$ and from 3.20 to 8.37 for $\beta$ of downstream slopes. Both the safety factors and reliability indices of the upstream slopes of earth core rockfill dams are higher than those of the downstream slopes. Thus, the stability of the downstream slope is the key failure mode of earth core rockfill dams.

Figures 6 to 8 also show that the safety factors and reliability indices of earth core rockfill dams are higher than those of concrete faced rockfill dams. This is mainly because earth core rockfill dams considered here have relatively gentle slopes compared to concrete faced rockfill dams.

It should be pointed out that the reliability indices in this section are a bit small, especially for dams higher than $250 \mathrm{~m}$. This happens because the statistical parameters reported by $\mathrm{Xu}$ (2010) [39] are the statistical results from 44 dams in China, and their divergences are relatively larger than those of a single dam. However, the behavior of the quantities is more important than their specific values. 


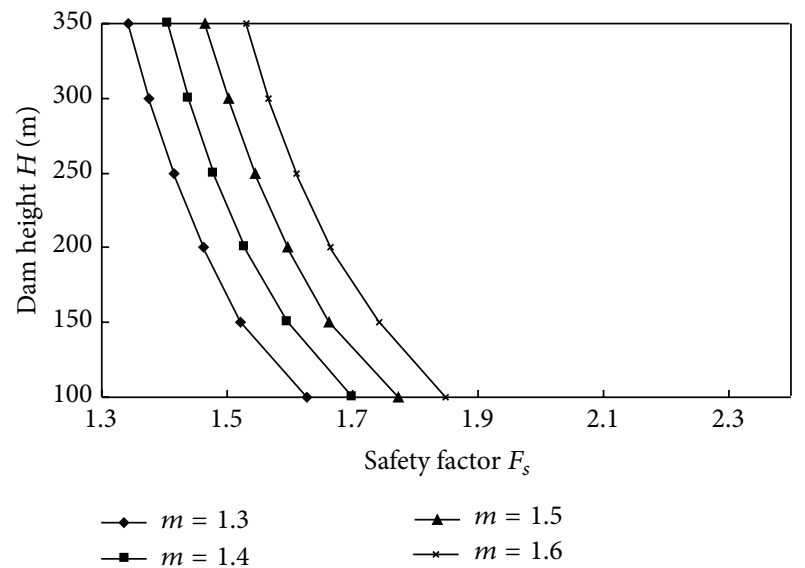

(a) Safety factor

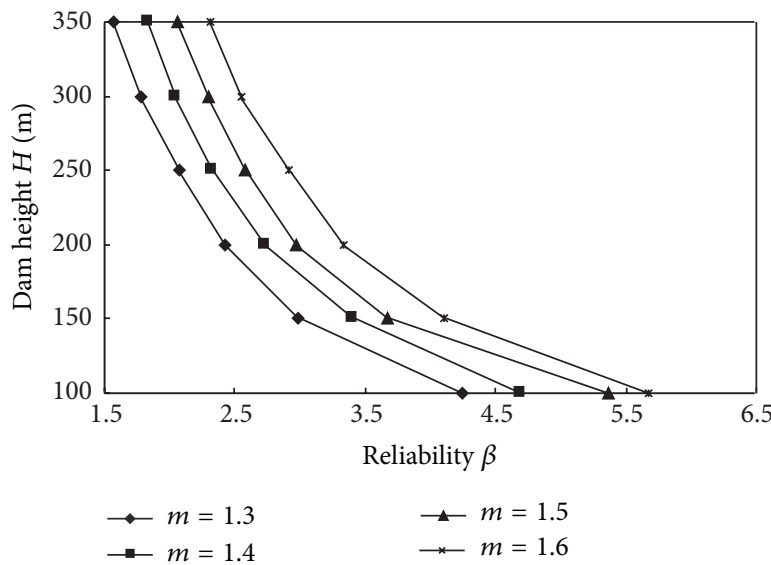

(b) Reliability index

FIGURE 6: Safety factors and reliability indices of downstream slopes of concrete faced rockfill dams.

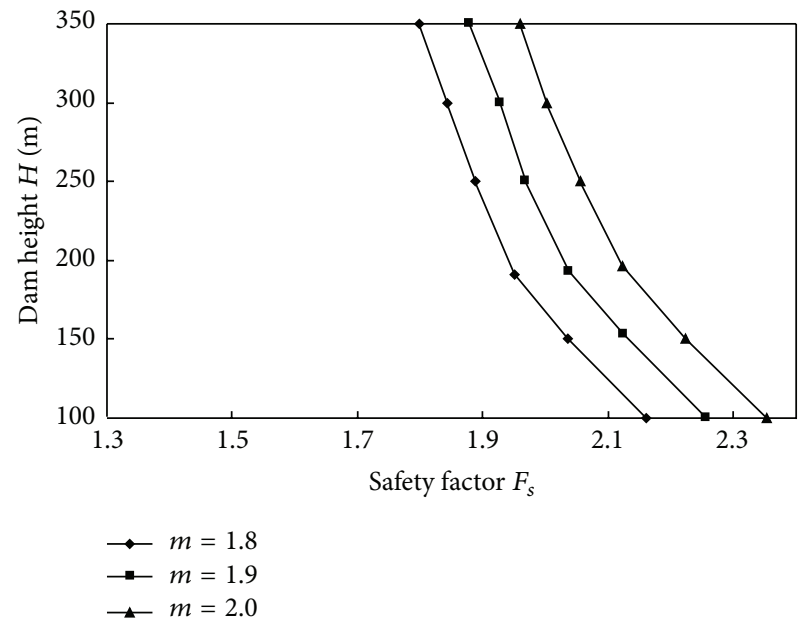

(a) Safety factor

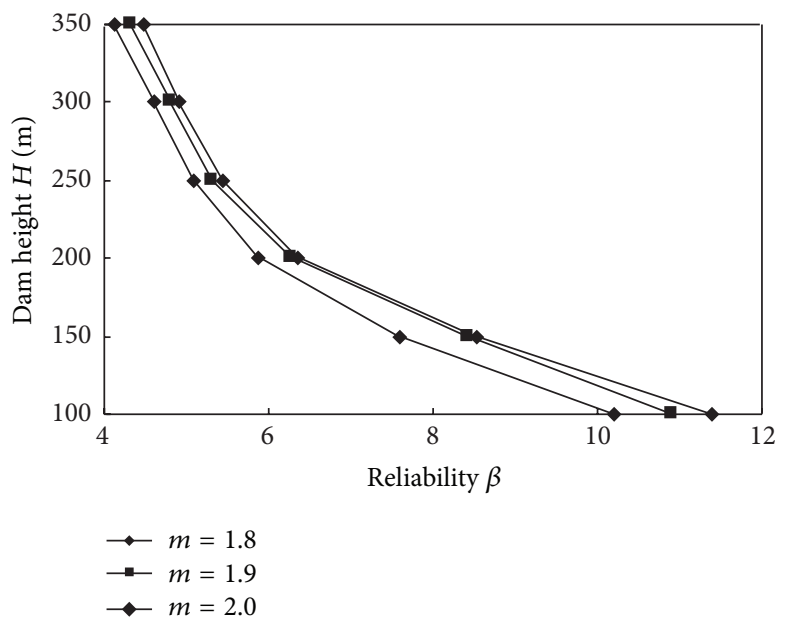

(b) Reliability index

FIGURE 7: Safety factors and reliability indices of upstream slopes of earth core dams.
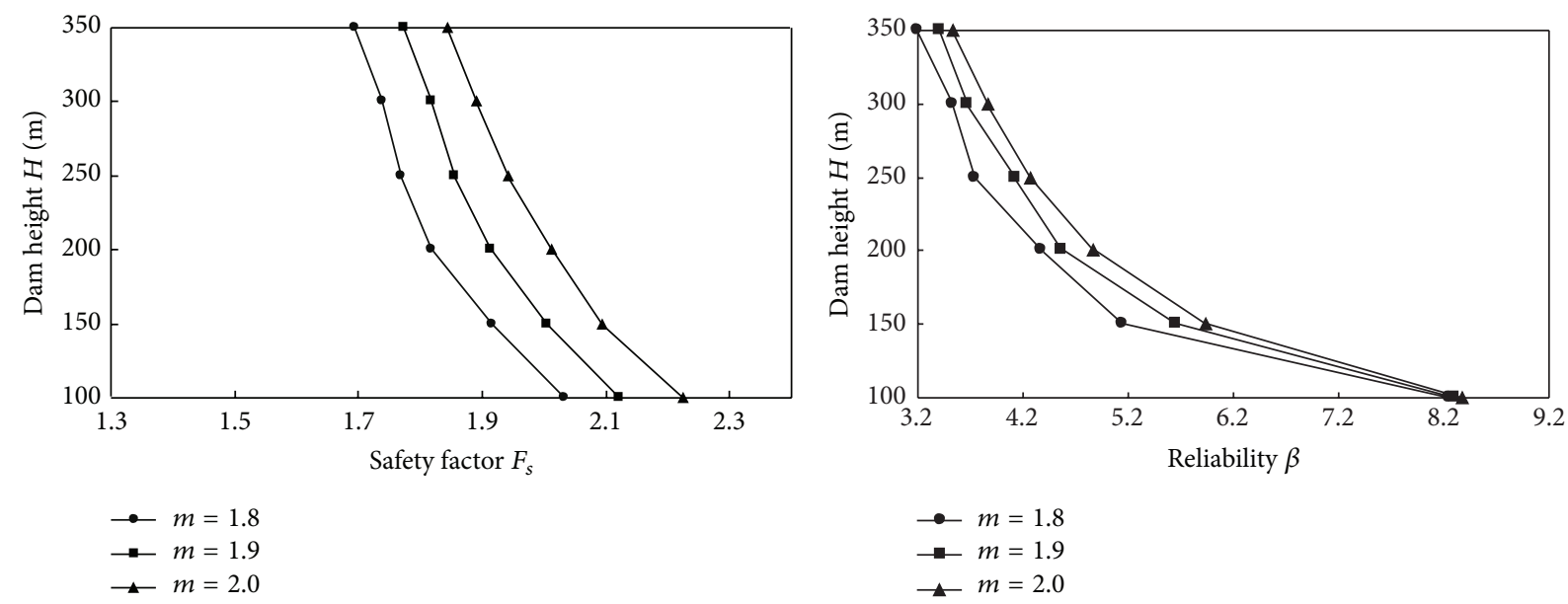

(a) Safety factor

(b) Reliability index

FIGURE 8: Safety factors and reliability indices of downstream slopes of earth core rockfill dams 


\section{Conclusions}

(1) A self-developed program 3DSTAB combining the slope stability analysis and reliability analysis is introduced. In this program, LEM is utilized to calculate the safety factor of the critical slip surface under static conditions. FORM, more precisely, the HL-RF iterative algorithm, is utilized to compute the reliability index corresponding to the critical probabilistic surface. When the derivatives of the performance function are calculated by the finite difference method in every iteration, a sequential approximation strategy is utilized. In other words, we do not search the critical slip surface under this circumstance, and the previous critical slip surface is saved and used, which improves the efficiency notably. Three examples reported in recent literature are studied and the comparisons prove the accuracy and validity of 3DSTAB.

(2) The dry bulk densities and shear strength parameters, including the linear strength parameters of earth core material and the nonlinear strength parameters of rockfill material, are taken as random variables. The truncated normal distribution is used for all normally distributed parameters to prevent negative sampling values. Because considering correlations between the parameters would only marginally increase the slope stability and its reliability, the correlations are not considered in this paper.

(3) Using the self-developed program 3DSTAB, the stability reliability analyses of concrete faced rockfill dams and earth core rockfill dams with different heights over $100 \mathrm{~m}$ and different slope ratios are performed. The results show that both the safety factors and reliability indices decrease as the dam's slope increases at a constant dam height and as the dam height increases at a constant slope ratio. More precisely, they decrease dramatically as the dam height increases from $100 \mathrm{~m}$ to $200 \mathrm{~m}$, while decrease slowly once the dam height exceeds $250 \mathrm{~m}$, which deserves extra attention.

Both the safety factors and reliability indices of the upstream slopes of earth core rockfill dams are higher than those of the downstream slopes. Thus, the stability of the downstream slope is the key failure mode of earth core rockfill dams.

\section{Conflict of Interests}

The authors declare that there is no conflict of interests regarding the publication of this paper.

\section{Acknowledgments}

This work is funded by the Key Project of Chinese National Programs for Fundamental Research and Development (2015CB057703), the National Natural Scientific Foundation of China (51138001), and the Fundamental Research Funds for the Central Universities (DUT14ZD206), which are gratefully acknowledged.

\section{References}

[1] Z.-Y. Chen and N. R. Morgenstern, "Extensions to the generalized method of slices for stability analysis," Canadian Geotechnical Journal, vol. 20, no. 1, pp. 104-119, 1983.

[2] N. Janbu, "Slope stability computation," in Embankment-Dam Engineering, R. C. Hirschfeld and S. J. Poulos, Eds., pp. 47-86, John Wiley \& Sons, New York, NY, USA, 1973.

[3] T. F. Wolff, "Probabilistic slope stability in theory and practice," in Proceedings of the Uncertainty in the Geologic Environment: From Theory to Practice, pp. 419-433, ASCE, Madision, Wis, USA, July-August 1996.

[4] G. J. Bureau, "Dams and appurtenant facilities," in Earthquake Engineering Handbook, W. F. Chen and C. Scawthorn, Eds., CRC Press, 2003.

[5] A. M. Yanmaz and M. R. Beser, "On the reliability-based safety analysis of Porsuk dam," Turkish Journal of Engineering \& Environmental Sciences, vol. 29, pp. 309-320, 2005.

[6] J. M. Duncan, "Factors of safety and reliability in geotechnical engineering," Journal of Geotechnical and Geoenvironmental Engineering, vol. 126, no. 4, pp. 307-316, 2000.

[7] A. M. Hassan and T. F. Wolff, "Search algorithm for minimum reliability index of earth slopes," Journal of Geotechnical and Geoenvironmental Engineering, vol. 125, no. 4, pp. 301-308, 1999.

[8] D. V. Griffiths and G. A. Fenton, "Probabilistic slope stability analysis by finite elements," Journal of Geotechnical and Geoenvironmental Engineering, vol. 130, no. 5, pp. 507-518, 2004.

[9] B. Xu and B. K. Low, "Probabilistic stability analyses of embankments based on finite-element method," Journal of Geotechnical and Geoenvironmental Engineering, vol. 132, no. 11, pp. 14441454,2006

[10] X. F. Luo, X. Li, J. Zhou, and T. Cheng, "A Kriging-based hybrid optimization algorithm for slope reliability analysis," Structural Safety, vol. 34, no. 1, pp. 401-406, 2012.

[11] E. Rosenblueth, "Point estimates for probability moments," Proceedings of the National Academy of Sciences of the United States of America, vol. 72, no. 10, pp. 3812-3814, 1975.

[12] R. Y. Liang, O. K. Nusier, and A. H. Malkawi, "A reliability based approach for evaluating the slope stability of embankment dams," Engineering Geology, vol. 54, no. 3-4, pp. 271-285, 1999.

[13] A. M. Hasofer and N. C. Lind, "Exact and invariant secondmoment code format," Journal of the Engineering Mechanics Division, vol. 100, no. 1, pp. 111-121, 1974.

[14] G. B. Baecher and J. T. Christian, Reliability and Statistics in Geotechnical Engineering, John Wiley \& Sons, Chichester, UK, 2003.

[15] G. L. S. Babu and A. Srivastava, "Reliability analysis of earth dams," Journal of Geotechnical and Geoenvironmental Engineering, vol. 136, no. 7, pp. 995-998, 2010.

[16] S. E. Cho, "Probabilistic stability analyses of slopes using the ANN-based response surface," Computers and Geotechnics, vol. 36, no. 5, pp. 787-797, 2009.

[17] K.-K. Phoon, Reliability-Based Design in Geotechnical Engineering, Taylor and Francis, New York, NY, USA, 2008.

[18] M. Hohenbichler and R. Rackwitz, "Non-normal dependent vectors in structural safety," Journal of Engineering Mechanics, vol. 107, no. 6, pp. 1227-1239, 1981.

[19] D. Val, F. Bljuger, and D. Yankelevsky, "Optimization problem solution in reliability analysis of reinforced concrete structures," Computers \& Structures, vol. 60, no. 3, pp. 351-355, 1996. 
[20] R. Rackwitz and B. Flessler, "Structural reliability under combined random load sequences," Computers \& Structures, vol. 9, no. 5, pp. 489-494, 1978.

[21] P.-L. Liu and A. der Kiureghian, "Optimization algorithms for structural reliability," Structural Safety, vol. 9, no. 3, pp. 161-177, 1991.

[22] A. W. Bishop, "The use of the slip circle in the stability analysis of slopes," Géotechnique, vol. 5, no. 1, pp. 7-17, 1955.

[23] N. Janbu, "Slope stability computations," Soil Mechanics and Foundation Engineering Report, The Technical University of Norway, Trondheim, Norway, 1968.

[24] H. Zheng, "Eigenvalue problem from the stability analysis of slopes," Journal of Geotechnical and Geoenvironmental Engineering, vol. 135, no. 5, pp. 647-656, 2009.

[25] H. Zheng, "A three-dimensional rigorous method for stability analysis of landslides," Engineering Geology, vol. 145-146, pp. 3040, 2012.

[26] J. M. Duncan, "State of the art: limit equilibrium and finiteelement analysis of slopes," Journal of Geotechnical Engineering, vol. 122, no. 7, pp. 577-596, 1996.

[27] L. Li, S. Chi, G. Lin et al., "Search for the critical slip surface using mixed version of particle swarm optimization algorithms," Industrial Construction, vol. 37, no. 2, pp. 55-59, 2007 (Chinese).

[28] E. O. F. Calle, "Probabilistic analysis of stability of earth slopes," in Proceedings of the 11th International Conference on Soil Mechanics and Foundation Engineering, pp. 809-812, Balkema, San Francisco, Calif, USA, August 1985.

[29] Y. Honjo and K. Kuroda, "A new look at fluctuating geotechnical data for reliability design," Soils and Foundations, vol. 31, no. 1, pp. 110-120, 1991.

[30] P. Yi, G. Cheng, and L. Jiang, "A sequential approximate programming strategy for performance-measure-based probabilistic structural design optimization," Structural Safety, vol. 30, no. 2, pp. 91-109, 2008.

[31] Z. Y. Chen, Soil Slope Stability Analysis: Theory, Methods and Programs, Water Pub Press, Beijing, China, 2003, (Chinese).

[32] Z. Y. Wu, J. K. Chen, W. L. Xu, B. Wen, and P. Zhang, "Research on methodology of reliability analysis of high rockfill dam slope stability using nonlinear strength indexes and its engineering application," Chinese Journal of Rock Mechanics and Engineering, vol. 28, no. 1, pp. 130-137, 2009 (Chinese).

[33] L.-H. Chen and Z.-Y. Chen, "Effect of nonlinear strength of rockfill on slope stability of high earth-rock dam," Rock and Soil Mechanics, vol. 28, no. 9, pp. 1807-1810, 2007 (Chinese).

[34] B. Indraratna, L. S. S. Wijewardena, and A. S. Balasubramaniam, "Large-scale triaxial testing of grey wacke rockfill," Geotechnique, vol. 43, no. 1, pp. 37-51, 1993.

[35] J. M. Duncan, "Strength, stress-strain and bulk modulus parameters for finite element analyses of stresses and movements in soil masses," Tech. Rep., The University of California, Berkeley, Calif, USA, 1980.

[36] S. T. Bai and Y. H. Cui, "The mechanical properties of rockfill," Journal of Hydroelectric Engineering, vol. 58, no. 3, pp. 21-30, 1994 (Chinese).

[37] Q. F. Lu and Z. Z. Yin, "Effect of strength nonlinearity on slope stability of high rockfill dam," Chinese Journal of Rock Mechanics and Engineering, vol. 23, no. 16, pp. 2708-2711, 2004 (Chinese).

[38] The Professional Standards Compilation Group of People's Republic of China, Design Code for Rolled Earth-Rock Fill Dams (SL274-2001), China Water Power Press, Beijing, China, 2002, (Chinese).
[39] C. Xu, Study on Reliability of Slope Stability of High Rockfill Dam, Dalian University of Technology, Dalian, China, 2010, (Chinese).

[40] T. Most and T. Knabe, "Reliability analysis of the bearing failure problem considering uncertain stochastic parameters," Computers and Geotechnics, vol. 37, no. 3, pp. 299-310, 2010.

[41] K. M. Cao and Z. W. Chen, "The stability analysis of rockfill dam using non-linear strength criterion," Water Resources and Hydropower Engineering, vol. 8, no. 9, pp. 37-42, 1991 (Chinese). 


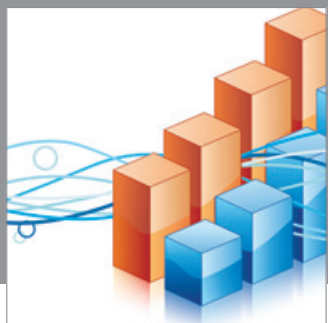

Advances in

Operations Research

mansans

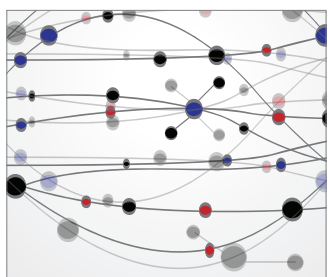

The Scientific World Journal
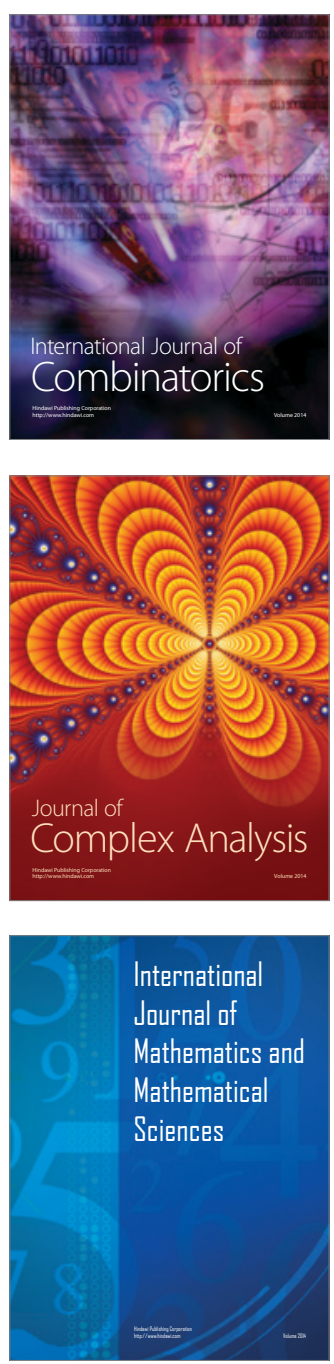
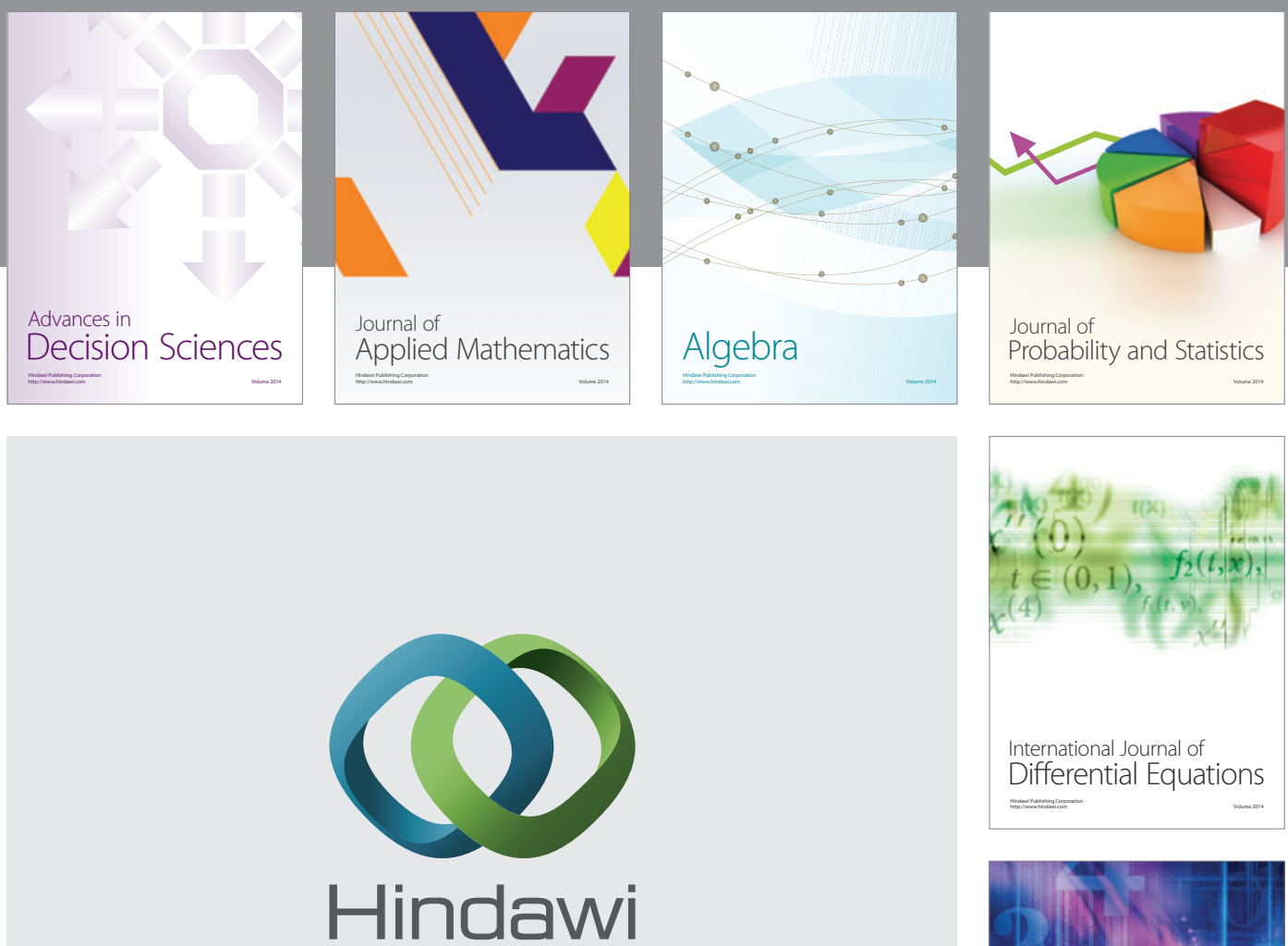

Submit your manuscripts at http://www.hindawi.com
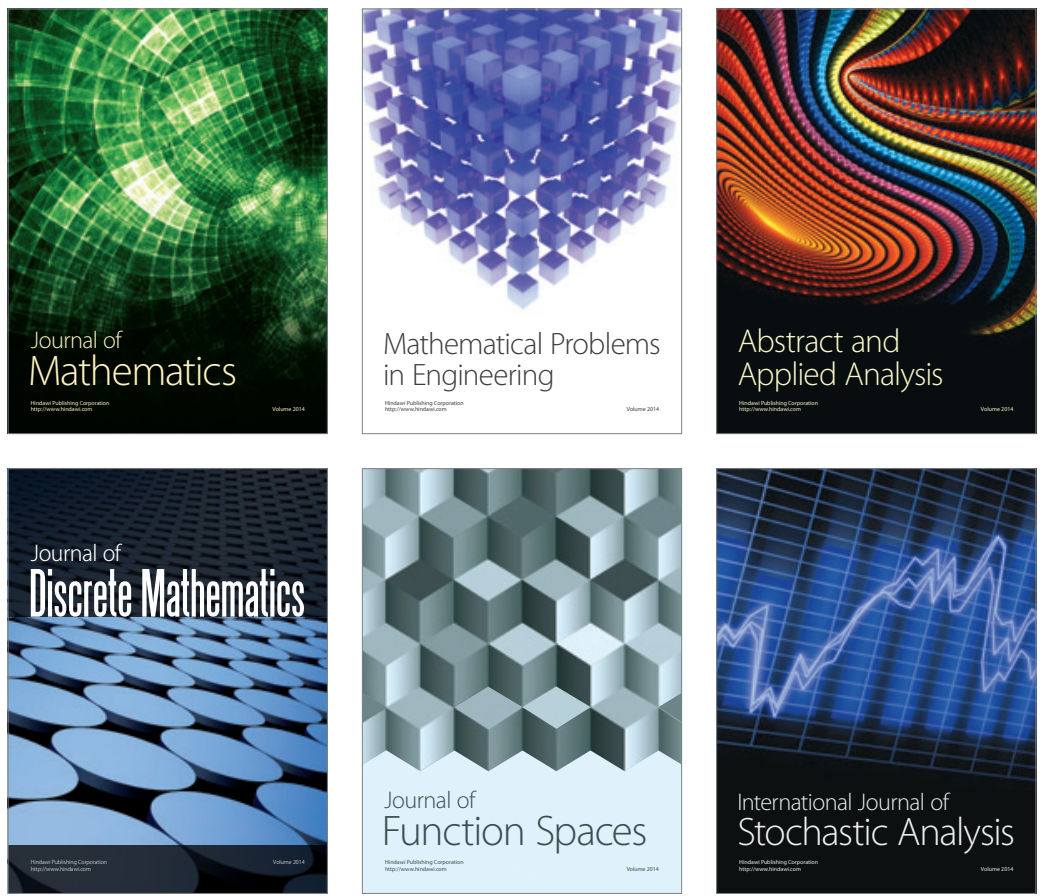

Journal of

Function Spaces

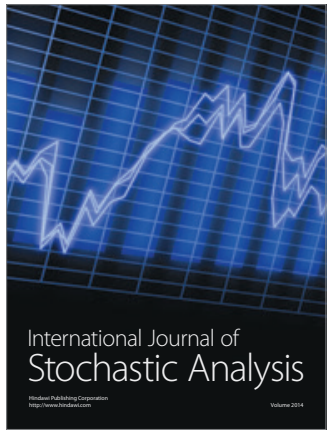

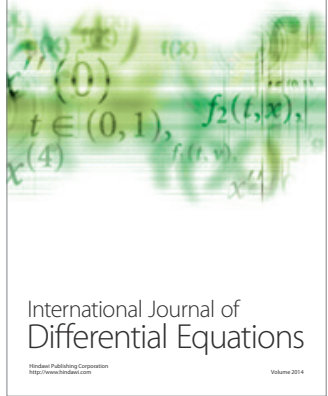
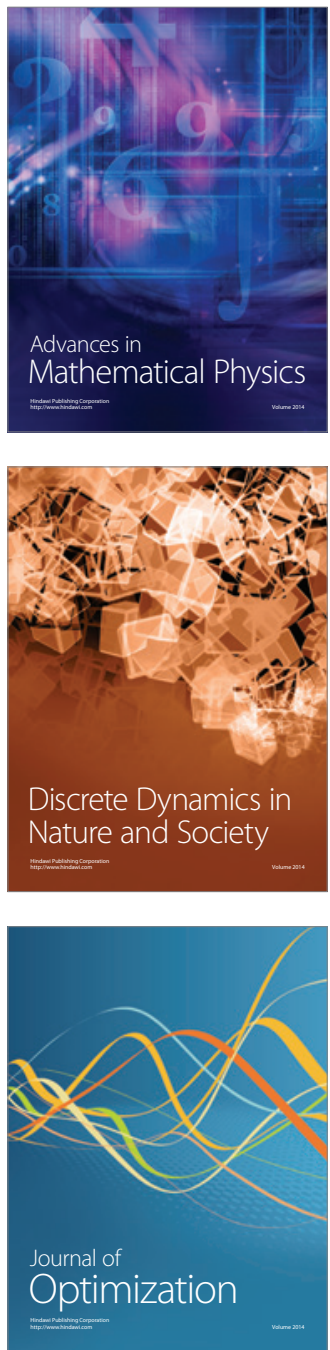